\title{
Patogenicidade de isolados de fungos entomopatogênicos à Spodoptera frugiperda (Smith) (Lepidoptera: Noctuidae)
}

\section{Patogenicity of entomopathogenic fungi to Spodoptera frugiperda (Smith) (Lepidoptera: Noctuidae)}

\author{
Dhyego Thomazoni ${ }^{1 *}$, Marina Andressa Formentini ${ }^{1}$, Luis Francisco Angeli Alves ${ }^{1,2}$
}

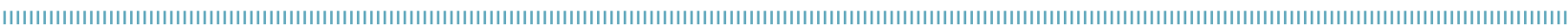

RESUMO: Este trabalho teve como objetivo avaliar a patogenicidade, em condiçôes de laboratório, de 49 isolados dos fungos entomopatogênicos das espécies Beauveria bassiana e Metarhizium anisopliae, contra lagartas de Spodoptera frugiperda. Lagartas de $3^{\circ}$ ínstar foram imersas em suspensôes de $1 \times 10^{9}$ conídios $/ \mathrm{mL}$ de cada um dos isolados por 10 segundos. Posteriormente, foram individualizadas em placas de Petri com dieta artificial, sendo incubadas a $26 \pm 1^{\circ} \mathrm{C}$ e 12 horas de fotofase, e avaliadas, diariamente, durante dez dias. Os isolados de $B$. bassiana mostraram-se mais eficientes, com destaque para o Unioeste 26 , que provocou $44,5 \%$ de mortalidade e gerou a maior quantidade de conídios nos testes de produção do fungo. Apesar da porcentagem de mortalidade baixa, tais estudos evidenciam potencial dos fungos entomopatogênicos como promissores agentes de controle de $S$. frugiperda.

PALAVRAS-CHAVE: fungos entomopatogênicos; controle microbiano; manejo integrado de pragas.

\begin{abstract}
This study aimed to evaluate the pathogenicity, under laboratory conditions, of 49 isolates of the entomopathogenic fungi Beauveria bassiana and Metarhizium anisopliae against Spodoptera frugiperda larvae. Insects ( $3^{\text {rd }}$ instar caterpillars) were immersed in $1 \times 10^{9}$ conidia/mL suspensions of each of the isolates for 10 seconds. After that, caterpillars were individually placed in Petri dishes with artificial diet and incubated at $26 \pm 1^{\circ} \mathrm{C}$ and 12 hours of photophase, and they were evaluated daily for ten days. The $B$. bassiana isolates were more efficient, mainly Unioeste 26 strain, which reached $44.5 \%$ mortality and generated the greatest number of conidia in production testing of the fungus. Despite the low mortality percentage, these studies showed the potential of entomopathogenic fungi as promising agents for the control of $S$. frugiperda.
\end{abstract}

KEYWORDS: entomopathogenic fungi; microbial control; integrated pest management. 


\section{INTRODUÇÃO}

A produção de grãos no Brasil é de grande importância para o agronegócio nacional. Diversas culturas têm alcançado destaque no cenário de produção mundial, dentre elas o milho, a soja, o feijão, o trigo e o arroz (Conab, 2013). Acompanhando esse crescimento, tais culturas tornaram-se alvo de diversas pragas, as quais afetam praticamente todas as fases de desenvolvimento das plantas e acarretam severos prejuízos no potencial produtivo dos grãos. Dentre as principais pragas, encontra-se Spodoptera frugiperda (Smith) (Lepidoptera: Noctuidae) (CruZ et al.,1999; GALlo et al., 2000).

Os produtos químicos têm sido utilizados para o controle da praga e, embora eficientes, podem afetar a qualidade do alimento, a saúde do agricultor e a do consumidor. Além disso, apresentam efeitos negativos sobre organismos não alvos, incluindo os inimigos naturais da praga. Isso causa um desequilíbrio biológico e ecológico. Além disso, os inseticidas vêm se tornando cada vez mais caros (DUARTE, 2000; Cruz et al., 2006).

Em função da importância da praga e também em relação ao aparecimento de populaçóes resistentes aos inseticidas, pesquisas envolvendo seu controle biológico têm aumentado. Deve-se considerar que os micro-organismos entomopatogênicos (fungos, bactérias e vírus) podem diminuir consideravelmente a população da praga no campo (WAQUIL et al., 2006). Nesse contexto, os fungos entomopatogênicos das espécies Beauveria bassiana (Bals.) Vuill. e Metarbizium anisopliae (Metsch.) Sorok. são de grande importância, e seu potencial contra a lagarta-do-cartucho tem sido demonstrado (GARDNER; FuXA, 1980; GARDNER et al., 1984; Chonay, 1988; Lezama et al., 1996; Lecuona, 1999; Carneiro et al., 2008; Wraight et al., 2010).

Assim, o objetivo do trabalho foi avaliar comparativamente a atividade de diferentes isolados brasileiros de $B$. bassiana e $M$. anisopliae contra lagartas de $S$. frugiperda, em laboratório.

\section{MATERIAL E MÉTODOS}

As lagartas utilizadas nos experimentos foram provenientes de criaçáo de laboratório, mantidas em copos plásticos de $50 \mathrm{~mL}$ com tampa perfurada contendo dieta artificial desde a eclosão dos ovos (Parra, 1999).

Foram avaliados 49 isolados de fungos entomopatogênicos pertencentes às espécies $B$. bassiana e $M$. anisopliae, provenientes das coleçôes "Oldemar Cardim Abreu", do Instituto Biológico de São Paulo, da Escola Superior de Agricultura "Luiz de Queiroz" (ESALQ/USP) e do Laboratório de Biotecnologia Agrícola da Unioeste, e mantidos em a $-10^{\circ} \mathrm{C}$ na forma de conídios puros (Tabela 1).

Os experimentos foram realizados em duas fases, sendo a primeira para selecionar isolados com potencial contra a praga em questáo e a segunda para compará-los, baseando-se na metodologia descrita e adotada por RoHDE et al. (2006).

\section{Seleção de isolados (patogenicidade)}

Os isolados foram multiplicados em placas de Petri contendo meio para produção de conídios (ME) (ágar $20 \mathrm{~g}$, extrato de levedura $5 \mathrm{~g}$, mistura de sais $4,6 \mathrm{~g}$, glicose $10 \mathrm{~g}$ e água destilada $1000 \mathrm{~mL}$ ) e incubadas a $26 \pm 1^{\circ} \mathrm{C}$ e 12 horas de fotofase, por sete dias (Alves et al., 1998). Após esse período, os conídios foram coletados pela raspagem da superfície do meio de cultura, sendo armazenados em tubos de vidro esterilizados, mantidos a $-10^{\circ} \mathrm{C}$. Previamente à realização dos experimentos, avaliou-se a viabilidade dos conídios ao inocular $100 \mu \mathrm{L}$ de uma suspensão de conídios ( 1 x $10^{5}$ conídios $/ \mathrm{mL}$ ) na superfície do meio de cultura BDA em placas de Petri (três placas para cada isolado). As placas foram incubadas por 16 a 24 horas em $26^{\circ} \mathrm{C}$ e a contagem de conídios germinados foi realizada em microscópio de luz $400 \mathrm{x}$ de aumento, considerando germinado o conídio que apresentava o tubo germinativo evidente.

Para os bioensaios, foram adicionados ao tubo $10 \mathrm{~mL}$ de água destilada contendo Tween $80(0,01 \%)$ e a suspensão foi agitada em vórtex para quantificaçáo em câmara de Neubauer a fim de padronizar a concentraçáo do fungo em $1 \times 10^{9}$ conídios $/ \mathrm{mL}$.

Em seguida, as lagartas foram imersas na suspensão de conídios dos diferentes isolados por 10 segundos, sob leve agitaçáo e transferidas para placas de Petri com dieta artificial (Parra, 1999), incubadas a $26 \pm 1^{\circ} \mathrm{C}$ e 12 horas de fotofase. Foram utilizadas 45 lagartas no $3^{\circ}$ ínstar para cada tratamento, sendo cada uma delas considerada uma repetiçáo. $\mathrm{Na}$ testemunha, as lagartas foram imersas apenas em água destilada estéril + Tween ${ }^{\circledR} 80$ (0,01\%).

Diariamente, durante dez dias, foram realizadas as avaliaçôes com a retirada dos cadáveres, que foram desinfestados por imersão em solução alcoólica $70 \%$ e água destilada, e depois mantidos em câmara úmida sob as mesmas condições citadas para a confirmação da mortalidade pelos fungos. Os isolados que ocasionaram as maiores porcentagens de mortalidade foram selecionados para a segunda fase.

\section{Comparação dos isolados}

Os isolados foram novamente multiplicados para serem comparados simultaneamente entre si por meio da avaliação do crescimento vegetativo, produção de conídios em meio de cultura, arroz e em cadáveres da lagarta-do-cartucho.

\section{Crescimento vegetativo}

Os conídios foram inoculados em dois pontos na superfície do meio de cultura ME, em placas de Petri, incubadas a 
Tabela 1. Origem e porcentagem de mortalidade confirmada de lagartas de Spodoptera frugiperda submetidas a diferentes isolados de Beauveria bassiana e Metarhizium anisopliae, após dez dias de incubação ( $26 \pm 1^{\circ} \mathrm{C}, 12$ horas de fotofase).

\begin{tabular}{|c|c|c|c|}
\hline Isolado & Hospedeiro original/substrato & Origem & $\begin{array}{c}\text { Mortalidade } \\
\text { confirmada (\%) }\end{array}$ \\
\hline \multicolumn{4}{|c|}{ Beauveria bassiana } \\
\hline Unioeste 01 & Astylus variegatus & Cascavel, (PR) & 33,3 \\
\hline Unioeste 02 & Alphitobius diaperinus & Cascavel, (PR) & 8,9 \\
\hline Unioeste 04 & Alphitobius diaperinus & Cascavel, (PR) & 4,4 \\
\hline Unioeste 05 & Alphitobius diaperinus & Cascavel, (PR) & 31,1 \\
\hline Unioeste 25 & Solo, plantação de erva-mate & Cascavel, (PR) & 15,6 \\
\hline Unioeste 26 & Solo, plantação de erva-mate & Cascavel, (PR) & 44,5 \\
\hline Unioeste 36 & Chrysomelidae & Cascavel, (PR) & 28,9 \\
\hline Unioeste 37 & Bombyx mori & Arapongas, (PR) & 22,2 \\
\hline Unioeste 38 & Bombyx mori & Ibaiti, (PR) & 11,1 \\
\hline Unioeste 39 & Cosmopolites sordidus & S. Miguel do Iguaçu, (PR) & 8,9 \\
\hline Unioeste 40 & Coleoptera, Curculionidae & Cascavel, (PR) & 0,0 \\
\hline Unioeste 41 & Astylus variegatus & Cascavel, (PR) & 0,0 \\
\hline Unioeste 42 & Coleoptera, Erotylidae & Cascavel, (PR) & 0,0 \\
\hline Unioeste 44 & Hemiptera, Pentatomidae & Toledo, (PR) & 4,4 \\
\hline Unioeste 45 & Astylus variegatus & Marechal C. Rondon, (PR) & 8,9 \\
\hline Unioeste 46 & Euschitus heros & Cascavel, (PR) & 4,4 \\
\hline Unioeste 47 & Hemiptera, Pentatomidae & Primavera do Leste, (MT) & 8,9 \\
\hline Unioeste 48 & Alphitobius diaperinus & Cascavel, (PR) & 8,9 \\
\hline Unioeste 49 & Alphitobius diaperinus & Cascavel, (PR) & 24,4 \\
\hline Unioeste 50 & Alphitobius diaperinus & Boa Vista da Aparecida, (PR) & 12,1 \\
\hline Unioeste 52 & Alphitobius diaperinus & B. Vista da Aparecida, (PR) & 22,2 \\
\hline Unioeste 53 & Alphitobius diaperinus & Cascavel, (PR) & 11,1 \\
\hline Unioeste 54 & Alphitobius diaperinus & Cascavel, (PR) & 2,2 \\
\hline Unioeste 55 & Alphitobius diaperinus & Cascavel, (PR) & 8,9 \\
\hline Unioeste 56 & Anthonomus grandis & Cascavel, (PR) & 7,5 \\
\hline Unioeste 57 & Hemiptera, Pentatomidae & Primavera do Leste, (MT) & 2,2 \\
\hline Unioeste 58 & Spodoptera frugiperda & Marechal C. Rondon, (PR) & 11,1 \\
\hline Unioeste 59 & Alphitobius diaperinus & Cascavel, (PR) & 8,9 \\
\hline Unioeste 60 & Chrysomelidae, Coleoptera & Catanduvas, (PR) & 20,0 \\
\hline Unioeste 61 & Coccinelidae & Marechal C. Rondon, (PR) & 11,1 \\
\hline Unioeste 62 & Alphitobius diaperinus & Cascavel, (PR) & 22,2 \\
\hline Unioeste 64 & Hedypathes betulinus & Cascavel, (PR) & 37,8 \\
\hline Unioeste 65 & Anthonomus grandis & Cascavel, (PR) & 17,8 \\
\hline Unioeste 66 & Anthonomus grandis & Cascavel, (PR) & 8,9 \\
\hline CG 716 & Hedypathes betulinus & Ivaí, (PR) & 11,1 \\
\hline \multicolumn{4}{|c|}{ Metarhizium anisopliae } \\
\hline Unioeste 22 & Solo, plantação de erva-mate & Cascavel, (PR) & 6,7 \\
\hline Unioeste 43 & Formicidae & São Miguel do Iguaçu, (PR) & 4,4 \\
\hline Unioeste 63 & Brassolis sophorae & Brasília, (DF) & 6,7 \\
\hline IBCB 167 & Solo & Cascavel, (PR) & 15,6 \\
\hline IBCB 351 & Solo - soja & Guariba, (SP) & 11,1 \\
\hline IBCB 353 & Mahanarva fimbriolata & Valparaíso, (SP) & 24,4 \\
\hline IBCB 360 & Solo - banana & Piedade, (SP) & 6,7 \\
\hline IBCB 383 & Mahanarva fimbriolata & Água Branca, (SP) & 26,7 \\
\hline IBCB 417 & Lagarta & Iporanga, (SP) & 33,3 \\
\hline IBCB 418 & Lagarta & Iporanga, (SP) & 4,4 \\
\hline IBCB 419 & Lagarta & Iporanga, (SP) & 20,0 \\
\hline IBCB 434 & Lagarta & Iporanga, (SP) & 17,8 \\
\hline ESALQ 06 & Diatraea saccharalis & Não disponível & 8,9 \\
\hline ESALQ 1104 & Solo & S. João do Piauí, (PI) & 11,1 \\
\hline
\end{tabular}


$26 \pm 1^{\circ} \mathrm{C}$ e 12 horas de fotofase, durante dez dias. Após esse período, foram realizadas duas mediçôes perpendiculares das colônias, visando-se obter seu diâmetro médio. Para cada um dos isolados foram preparadas cinco placas, sendo cada uma delas uma repetição.

\section{Produção de conídios em meio de cultura}

Após avaliação do crescimento vegetativo, as colônias foram recortadas do meio de cultura na linha terminal do halo e transferidas, individualmente, para tubos de vidro. Para a avaliaçâao, as colônias foram imersas em $10 \mathrm{~mL}$ de solução de água destilada esterilizada contendo Tween $80(0,01 \%)$ e agitadas em vórtex por um minuto para o desprendimento dos conídios. A quantificaçâo foi realizada em câmara de Neubauer, em microscópio óptico.

\section{Produção de conídios em arroz}

Este parâmetro foi avaliado por meio do método do Biomax ${ }^{\circledR}$ (Alves; Pereira, 1989). Para tal, sacos de polipropileno contendo $200 \mathrm{~g}$ de arroz polido e pré-cozido por 3 minutos em água fervente foram autoclavados por 15 minutos a $120^{\circ} \mathrm{C}$. Após o resfriamento, foi realizada a inoculaçáo de $10 \mathrm{~mL}$ da suspensão de conídios produzidos previamente em $\mathrm{ME}$, sendo que para cada isolado foram preparadas três repetiçóes, com dez sacos para cada uma.

Os sacos foram incubados a $26 \pm 1^{\circ} \mathrm{C}$ e 12 horas de fotofase durante sete dias. Posteriormente, foram abertos, e seu conteúdo ficou exposto a um fluxo de ar em bandejas de plástico em câmara asséptica por quatro dias, sob temperatura de $25 \pm 1^{\circ} \mathrm{C}$ e 24 horas de fotofase. Em seguida, efetuou-se a avaliação da produção de conídios/g, seguindo procedimentos descritos por Leite et al. (2003).

\section{Avaliação de tempo de contato e produção de conídios em cadáveres da lagarta-do-cartucho}

Considerando que uma provável forma de utilização do fungo no campo seria a aplicação direta dos grãos de arroz, frente ao comportamento e local de abrigo da lagarta nas plantas, os isolados foram novamente produzidos em arroz, utilizando o mesmo procedimento experimental descrito anteriormente. Após dez dias de incubação, o experimento foi instalado preparando-se placas de Petri $(9 \mathrm{~cm}$ de diâmetro) com o fundo recoberto por arroz + fungo. Em seguida, 15 lagartas de $3^{\circ}$ ínstar foram transferidas para uma placa a fim de percorrerem o substrato em intervalos de tempo de 5 e 10 minutos. Nos respectivos tempos, os insetos foram retirados e mantidos em placas de Petri contendo uma porção de dieta artificial $(2 \mathrm{~cm} \mathrm{x} 1 \mathrm{~cm} \times 1 \mathrm{~cm}$ : largura $\mathrm{x}$ comprimento $\mathrm{x}$ altura). Para cada isolado e para cada tempo foram preparadas três placas, sendo cada uma considerada uma repetição. No caso da testemunha, nenhum tratamento foi aplicado nas lagartas. Os insetos mortos foram retirados e transferidos para câmara úmida para confirmação da mortalidade pelo fungo. Para estimar a produção de conídios foram selecionados, em cada repetição, dez cadáveres que apresentavam o corpo recoberto por conídios, que foram individualizados em tubos de vidro de fundo chato com $10 \mathrm{~mL}$ de água destilada e Tween $80 \mathrm{a}$ 0,01\%. Em seguida, os conídios da superfície dos insetos foram removidos com auxílio de pincel, a suspensão foi agitada em vórtex durante um minuto e quantificada em câmara de Neubauer.

Os dados obtidos foram analisados estatisticamente segundo o delineamento inteiramente casualizado e, para interaçấo do efeito dos diferentes fatores (isolados e o tempo de contato), foi adotado o esquema fatorial 4 × 2 ( 4 isolados de fungos $\mathrm{x} 2$ intervalos de tempo), dispostos em parcelas subdivididas no tempo, utilizando o programa estatístico Sisvar (Ferreira, 2011).

Para os demais parâmetros avaliados na comparaçáo dos isolados, os dados foram transformados quando necessário e submetidos à análise de variância (teste F), sendo as médias comparadas pelo teste de Tukey, ambos a 5\% de significância, segundo o delineamento experimental inteiramente aleatorizado, utilizando-se o programa estatístico Sisvar (Ferreira, 2011).

\section{RESULTADOS E DISCUSSÃO}

\section{Seleção de isolados (avaliação da patogenicidade)}

Todos os isolados apresentaram viabilidade entre 85 e 95\%. A maioria dos isolados testados foi patogênica à $S$. frugiperda, entretanto, o inseto apresentou pouca suscetibilidade aos fungos testados, visto que, no geral, a mortalidade confirmada foi no máximo próxima a $44 \%$. Verificou-se também grande variação entre os isolados (Tabela 1).

Os maiores percentuais de mortalidade confirmados foram obtidos com isolados de B. bassiana, com destaque para Unioeste 26, com o qual se obteve a maior porcentagem de mortalidade confirmada dentre todos os isolados avaliados (44,5\%); logo após veio Unioeste 64 e Unioeste 1, com 37,8 e 33,3\%, respectivamente, sendo também pertencentes à $B$. bassiana.

Em relação aos isolados de $M$. anisopliae, IBCB 417 foi o que provocou a maior porcentagem de mortalidade confirmada, com $33,3 \%$.

A maior atividade dos isolados de $B$. bassiana pode ser atribuída à capacidade das espécies desse gênero para produzir 
uma variedade de metabólitos secundários que estão envolvidos na patogênese e na virulência, se comparadas a outros fungos entomopatogênicos. Além disso, análises genéticas indicaram que $B$. bassiana possui mais proteínas e enzimas envolvidas no metabolismo celular e um maior número de genes que expressam toxinas semelhantes às de bactérias em relação a outras espécies de fungos entomopatogênicos (XIAO et al., 2012).

Em estudos de seleçáo de isolados, a variação na patogenicidade é observada com frequência, sendo relacionada à virulência do isolado, à especificidade e à tolerância do hospedeiro, consequência da variabilidade genética de cada isolado (Alves, 1998).

Nesse sentido, Rohde et al. (2006), Kaur; Padmaja (2008) e CARNEIRO et al. (2008) avaliaram a suscetibilidade de fungos entomopatogênicos contra Alphitobius diaperinus, Spodoptera litura e $S$. frugiperda, respectivamente, e também constataram ampla variação na patogenicidade entre os isolados avaliados de uma mesma espécie de fungo.

Resultados promissores foram observados ao avaliar a suscetibilidade de $B$. bassiana e $M$. anisopliae testados a $1 \times$ $10^{8}$ conídios $/ \mathrm{mL}$ sobre $S$. litura, verificando, após o sexto dia da inoculação dos fungos, $100 \%$ de mortalidade para todos os dez isolados testados (Petlamul; Prasertsan, 2012).

Estudos para verificação da virulência de $B$. bassiana e $M$. anisopliae sobre $S$. litura constataram que a porcentagem de mortalidade foi dependente da dose e do ínstar larval, visto que a maior concentração de $M$. anisopliae avaliada ocasionou a maior taxa de mortalidade para o menor instar larval (Sahayaraj; Borgio, 2010). Além disso, verificou-se também que a maior concentração de B. bassiana testada também acarretou as maiores reduçóes do período larval, da emergência de adultos, da longevidade, da fecundidade e da eclosão dos ovos de S. litura (Kaur et al., 2011).

Embora os resultados aqui obtidos não sejam tão expressivos, assemelham-se aos encontrados na literatura, que relata a baixa suscetibilidade de lagartas de $S$. frugiperda ao fungo B. bassiana, sendo desconhecidas as razóes para isso, mesmo que lagartas desta espécie sejam frequentemente encontradas infectadas e mortas por B. bassiana em campo (GARDNER; FuXA, 1980; Gardner et al., 1984; Pérez; Ruíz, 1998; PolanczyK; Alves, 2005; Wraight et al., 2010). Isso comprova a importância da realização de bioensaios de seleção de isolados para a obtenção daqueles mais eficientes.

Assim, foram selecionados para os estudos posteriores os isolados Unioeste 1, Unioeste 26 e Unioeste 64 (B. bassiana) e um isolado de $M$. anisopliae (IBCB 417).

\section{Comparação dos isolados}

\section{Crescimento vegetativo}

Observou-se que houve variação no diâmetro das colônias entre os isolados e que não houve predominância de nenhuma das espécies em relação ao tamanho das colônias, já que as maiores foram obtidas com o isolado IBCB 417 de $M$. anisopliae $(3,5 \mathrm{~cm})$ e UNIOESTE 1 de $B$. bassiana, com 3,2 cm (Tabela 2).

Variaçóes no tamanho do diâmetro de colônias entre isolados de ambos os fungos citados foram verificadas previamente, com médias que variaram entre $2,9 \mathrm{~cm}$ e 4,3 cm, após dez dias de incubação a $26^{\circ} \mathrm{C}$ (Rohde et al., 2006; SANTORo et al., 2008). Da mesma forma, Petlamul; Prasertsan (2012), também observaram taxas de crescimento de colônias variaram de 20 a $40 \mathrm{~mm} /$ dia, após 15 dias de incubação a $29^{\circ} \mathrm{C}$.

\section{Produção de conídios em meio de cultura}

O isolado UNIOESTE 26 destacou-se em relação aos demais isolados analisados, independentemente de se analisar produçáo de conídio/ $\mathrm{cm}^{2}\left(10,5 \times 10^{8}\right)$ ou na colônia inteira $\left(2,4 \times 10^{8}\right)$. Os demais isolados mantiveram produção média de $1,8 \times 10^{8}$ conídios/colônia, não havendo diferenças significativas na produção média de conídios $/ \mathrm{cm}^{2}$ (Tabela 2).

Valores próximos aos relatados neste estudo foram observados por RoHDE et al. (2006), que obtiveram produção de até $3,2 \times 10^{8}$ conídios $/ \mathrm{cm}^{2}$ ao avaliarem outros isolados de

Tabela 2. Diâmetro médio de colônias ( \pm EP) e produção de conídios ( \pm EP) de Beauveria bassiana e Metarhizium anisopliae em meio de cultura e arroz, após dez e sete dias de incubação, respectivamente ( $26 \pm 1^{\circ} \mathrm{C}, 12$ horas de fotofase).

\begin{tabular}{lcccc} 
Isolados & Diâmetro $(\mathrm{cm})$ & $\begin{array}{c}\text { Produção de } \\
\text { conídios/colônia* } \\
\text { Beauveria bassiana }\end{array}$ & $\begin{array}{c}\text { Produção média } \\
\text { de conídios/cm }\end{array}$ & $\begin{array}{c}\text { Produção de } \\
\text { conídios/arroz/g* }\end{array}$ \\
\hline UNIOESTE 01 & $3,2 \pm 0,04 \mathrm{~A}$ & $1,8 \pm 1,60 \mathrm{~B}$ & $2,3 \pm 0,76 \mathrm{~B}$ & $1,2 \pm 0,01 \mathrm{~B}$ \\
\hline UNIOESTE 26 & $1,7 \pm 0,06 \mathrm{C}$ & $2,4 \pm 0,89 \mathrm{~A}$ & $10,5 \pm 1,03 \mathrm{~A}$ & $1,6 \pm 0,00 \mathrm{~A}$ \\
\hline UNIOESTE 64 & $2,8 \pm 0,16 \mathrm{~B}$ & $1,8 \pm 0,67 \mathrm{~B}$ & $2,9 \pm 0,89 \mathrm{~B}$ & $1,2 \pm 0,02 \mathrm{~B}$ \\
\hline & \multicolumn{7}{c}{ Metarhizium anisopliae } & $2,0 \pm 0,64 \mathrm{~B}$ & $1,3 \pm 0,04 \mathrm{~B}$ \\
\hline IBCB 417 & $3,5 \pm 0,06 \mathrm{~A}$ & $1,8 \pm 1,04 \mathrm{~B}$ & 5,67 & 2,51 \\
\hline CV (\%) & 7,99 & 2,51 & &
\end{tabular}

*número médio de conídios x $10^{8} ;{ }^{* *}$ número médio de conídios $\times 10^{7}$.

Dados originais apresentados: para análise estatística, os dados de produção de conídios em meio de cultura e arroz foram transformados em Médias ( \pm erro padrão) seguidas pela mesma letra na coluna não diferem entre si, pelo teste de Tukey $(p<0,05)$. 
B. bassiana. Ainda, SANTORO et al. (2008) encontraram valores entre $24,7 \times 10^{7}$ e $50,1 \times 10^{7}$ conídios $/ \mathrm{cm}^{2}$, avaliando diferentes isolados do mesmo fungo, sendo essa ampla variaçáo também verificada por Petlamul; Prasertsan (2012) em relação à $B$. bassiana e $M$. anisopliae. O fato comum pode ser explicado pela grande variabilidade genética entre os diferentes isolados de uma mesma espécie.

Ressalta-se que no presente estudo não houve relação direta entre a produção de conídios e o tamanho das colônias, uma vez que o isolado IBCB 417 que apresentou o maior diâmetro levou à menor produção de conídios das colônias $/ \mathrm{cm}^{2}$, enquanto o UNIOESTE 26, que demonstrou o menor diâmetro de colônia, foi o isolado mais produtivo, tal como também observado por RoHDE et al. (2006) e Santoro et al. (2008).

\section{Produção de conídios em arroz}

O isolado UNIOESTE 26 proporcionou a maior produção, apresentando 1,6 $\times 10^{8}$ conídios/g de arroz, sendo significativamente superior aos demais isolados (Tabela 2).

Entretanto, a produçáo de conídios em arroz dos isolados aqui avaliados, em geral, foi considerada baixa se comparada aos trabalhos realizados por Leite et al. (2003), Neves; Hirose (2005) e Rohde et al. (2006), que obtiveram, respectivamente, $6,0 \times 10^{9} ; 8,84 \times 10^{8}$ e $8,3 \times 10^{8}$ conídios/g de arroz com outros isolados de $B$. bassiana.

Tais diferenças podem ser explicadas tanto pelas variaçôes no método empregado como pela quantidade de substrato em cada recipiente, quantidade de inóculo aplicado, tipo e qualidade do arroz, teor de umidade e tempo de incubação (РотRich et al., 2006).

É importante ressaltar que, em geral, fatores como fotoperíodo, temperatura e umidade relativa e, ainda, as variaçóes no tempo de incubação, no tipo e na espessura do meio de cultura utilizado, além da variabilidade genética dos isolados, podem interferir no desenvolvimento dos diferentes isolados, explicando as variaçóes obtidas no presente estudo (Alves, 1998; РотRICH et al., 2006).

\section{Avaliação de tempo de contato e produção de conídios em cadáveres da lagarta-do-cartucho}

Os cadáveres de $S$. frugiperda apresentaram conidiogênese com todos os isolados, exceto o UNIOESTE 1, após 5 minutos de contato, sendo também este o isolado que menos produziu conídios ao fim da avaliação.

Entre B. bassiana, o isolado UNIOESTE 26 mostrou novamente superioridade na produção de conídios, com produção média de $5,7 \times 10^{7}$ conídios/cadáver após 10 minutos de contato. Entretanto, IBCB 417 de M. anisopliae foi o que se destacou, diferindo significativamente dos demais, visto que a produção em cadáveres alcançou 7,4 x $10^{7}$ conídios/cadáver quando exposto também ao maior tempo de contato (Tabela 3).

Tabela 3. Número médio de conídios ( \pm EP) de isolados de Beauveria bassiana e Metarhizium anisopliae obtido em cadáveres da lagarta-do-cartucho do milho em diferentes intervalos de tempo de contato, após 10 dias de incubação (26 $\pm 1^{\circ} \mathrm{C}, 12$ horas de fotofase).

\begin{tabular}{lcc} 
Isolados/Tempo & Tempo de contato (minutos) \\
\cline { 2 - 3 } & 5 & 10 \\
& Beauveria bassiana \\
\hline UNIOESTE 1 & ${ }^{*} \mathrm{O} \pm 0,00 \mathrm{Cb}$ & $2,5 \pm 0,07 \mathrm{Ca}$ \\
\hline UNIOESTE 26 & $2,4 \pm 0,22 \mathrm{Ab}$ & $5,7 \pm 0,19 \mathrm{Ba}$ \\
\hline UNIOESTE 64 & $2,4 \pm 0,22 \mathrm{Ab}$ & $3,1 \pm 0,09 \mathrm{Ca}$ \\
\hline \multicolumn{3}{c}{ Metarhizium anisopliae } \\
\hline IBCB 417 & $5,1 \pm 0,06 \mathrm{Ab}$ & $7,4 \pm 0,29 \mathrm{Aa}$ \\
\hline CV $(\%)=12,03$ & & \\
\hline
\end{tabular}

${ }^{*}$ número médio de conídios por cadáver x $10^{7}$; **não ocorreu mortalidade confirmada neste estágio de desenvolvimento do inseto; Médias ( \pm erro padrão) seguidas pela mesma letra maiúscula na coluna e minúscula na linha não diferem significativamente entre si pelo teste de Tukey $(p<0,05)$.

Em geral, verificou-se que houve um aumento na quantidade de conídios dos cadáveres com relação ao tempo de contato para todos os isolados avaliados. Possivelmente, isso se deve ao fato de o maior tempo ter propiciado maior quantidade de conídios aderidos ao corpo da lagarta, aumentando assim o potencial de inóculo (Alves; Lecuona, 1998).

Vale ressaltar que estudos de comparação de isolados pré-selecionados remetem apenas à produção de conídios em cadáveres, excluindo a relaçấo do tempo de contato com a produçáo de conídios nos cadáveres, então esses resultados são escassos. Contudo, um experimento similar, em que adultos de $A$. diaperinus foram imersos por diferentes períodos de tempo em suspensão de conídios de $B$. bassiana, também constatou que a mortalidade confirmada aumentou significativamente à medida que o tempo de imersão também foi maior (SANTORO et al., 2007).

\section{CONCLUSÃO}

Os isolados de B. bassiana apresentaram maior patogenicidade contra lagartas de $S$. frugiperda, com destaque para o UNIOESTE 26, com o qual também se teve a maior produção de conídios em meio de cultura e em arroz. 


\section{REFERÊNCIAS}

ALVES, S.B.; PEREIRA, R.W. Produção de Metarhizium anisopliae (Metsch.) Sorok. e Beauveria bassiana (Bals.) Vuill. em bandejas. Ecossistema, v.14, p.188-192, 1989.

ALVES, S.B. Fungos entomopatogênicos. In: ALVES, S.B. (Ed.). Controle microbiano de insetos. 2.ed. Piracicaba: FEALQ. 1998. p.308-310.

ALVES, S.B.; LECUONA, R.E. Epizootiologia aplicada ao controle microbiano de insetos. In: ALVES, S.B. Controle microbiano de insetos. 2.ed., Piracicaba: FEALQ. 1998. p.97-169.

ALVES, S.B.; ALMEIDA, J.E.M.; MOINO JR., A.; ALVES, L.F.A. Técnicas de laboratório. In: ALVES, S.B. (Ed.). Controle microbiano de insetos. 2.ed., Piracicaba: FEALQ. 1998. p.637-711.

CARNEIRO, A.A.; GOMES, E.A.; GUIMARÃES, C.T; FERNANDES, F.T.; CARNEIRO, N.P.; CRUZ, I. Molecular characterization and pathogenicity of isolates of Beauveria spp. to fall armyworm. Pesquisa Agropecuária Brasileira, v.43, p.513-520, 2008.

CONAB. Acompanhamento da Safra Brasileira de Grãos 2012/13 - Terceiro Levantamento - Outubro/2013. Disponível em: http://www.conab.gov.br/OlalaCMS/uploads/ arquivos/13_12_10_16_06_56_boletim_portugues_ dezembro_2013.pdf>. Acesso em: 12 dez. 2013.

CHONAY, M.F.C. Determinación de la patogenicidad del entomopatógeno Beauveria bassiana (Bals.) Vuill en 20 especies de insectos plaga en condiciones de laboratorio y su efecto a nivel de campo em Pieris sp. 1988. 23f. Tese (Mestrado) - Universidade Federal de São Carlos, 1988.

CRUZ, I.; VIANA, P.A.; WAQUIL, J.M. Manejo das pragas iniciais de milho mediante o tratamento de sementes com inseticidas sistêmicos. Sete Lagoas: EMBRAPA MILHO E SORGO, 1999. 39p. (Circular Técnica 31).

CRUZ, I.; VIANA, P.A.; WAQUIL, J.M. Pragas da fase vegetativa e reprodutiva do milho. Sete Lagoas: EMBRAPA MILHO E SORGO, 2006. (Documento Técnico). Disponível em: <http:// sistemasdeproducao.cnptia.embrapa.br/FontesHTML/Milho/ CultivodoMilho_2ed/prvegetativa.htm>. Acesso em: 12 ago. 2012.

DUARTE, J.O. Importância econômica do milho. Sete Lagoas: EMBRAPA MILHO E SORGO, 2000. (Documento Técnico). Disponível em: < http://sistemasdeproducao.cnptia.embrapa.br/ FontesHTML/Milho/CultivodoMilho/importancia.htm>. Acesso em: 18 ago. 2012.

FERREIRA, D.F. Sisvar: a computer statistical analysis system. Ciência e Agrotecnologia, Lavras, v.35, n.6, p.1039-1042, 2011.

GALLO, D.; NAKANO, O.; NETO, S.S.; CARVALHO, R.P.L.; BAPTISTA, G.C.; FILHO, E.B.; PARRA, J.R.P.; ZUCCHI, R.A.; ALVES, S.B.; VENDRAMIM, J.D.; MARCHINI, L. C.; LOPES, J.R.S.; OMOTO, C. Entomologia Agrícola, v.1. Piracicaba: FEALQ, 2002.

GARDNER, W.A.; FUXA, J.R. Pathogens for the suppression of the fall armyworm. Florida Entomologist, v.63, p.439-447, 1980.
GARDNER, W.A.; NOBLET, R.; SCWEHR, R. The potential of microbial agents in managing populations of the fall armyworm (Lepidoptera: Noctuidae). Florida Entomologist, v.67, p.325-332, 1984.

KAUR, G.; PADMAJA, V. Evaluation of Beauveria bassiana isolates for virulence against Spodoptera litura (Fab.) (Lepidoptera: Noctuidae) and their characterization by RAPD-PCR. African Journal of Microbiology Research, v.2, p.299-307, 2008.

KAUR, S.; KAUR, H.P.; KAUR, K.; KAUR, A. Effect of different concentrations of Beauveria bassiana on development and reproductive potential of Spodoptera litura (Fabricius). Journal of Biopesticides, v.4, p.161-168, 2011.

LECUONA, R. Microbial control with entomopathogenic fungi in Argentina. Revista de la Sociedad Entomológica Argentina, v.58, p.301-306, 1999.

LEITE, L.G.; BATISTA FILHO, A.; ALMEIDA, J.E.M.; ALVES, S.B. Produção de fungos entomopatogênicos. Ribeirão Preto: A.S. Pinto. 2003. 92p.

LEZAMA, G.R.; ALATORRE, R.R.; BODAJIL, J.L.F. Virulencia de cinco cepas de los hongos entomopatogenos contra Spodoptera frugiperda (Lepidoptera: Noctuidae) en huevos y larvas neonatas. Revista Internacional de Control Biológico, v.23, p.35-39, 1996.

NEVES, P.M.O.J.; HIROSE, E. Seleção de isolados de Beauveria bassiana para o controle biológico da broca-do-café, Hypothenemus hampei (Ferrari) (Coleoptera: Scolytidae). Neotropical Entomology, v.34, p.77-82, 2005.

PARRA, J.R.P. Técnicas de criação de insetos para programas de controle biológico. Piracicaba: ESALQ/FEALQ. 1999. 137p.

PÉREZ, C.R.; RUIZ, R.V.; Patogenecidad de hongos entomopatógenos de plagas del arroz. Arroz, v.47, p.24-30, 1998.

PETLAMUL, W., PRASERTSAN, P. Evaluation of strains of Metarhizium anisopliae and Beauveria bassiana against Spodoptera litura on the basis of their virulence, germination rate, conidia production, radial growth and enzyme activity. Mycobiology, v.40, p. $111-116,2012$.

POLANCZYK, R.A.; ALVES, S.B. Interação entre Bacillus thuringiensis e outros entomopatógenos no controle de Spodoptera frugiperda. Manejo Integrado de Plagas y Agroecología, n.74, p.24-33, 2005.

POTRICH, M.; ALVES, L.F.A.; MERTZ, N.R.; SILVA, E.R.L. Avaliação de Beauveria bassiana (Bals.) Vuill. e Metarhizium anisopliae (Metsch.) Sorok. para controle de Sitophilus zeamais (Coleoptera: Curculionidae). Bioassay, v. 1, 2006.

ROHDE, C.; ALVES, L.F.A.; NEVES, P.M.O.J.; ALVES, S.B.; SILVA, E.R.L.; ALMEIDA, J.E.M. Seleção de isolados de Beauveria bassiana (Bals.) Vuill. E Metarhizium anisopliae (Metsch.) Sorok. contra o cascudinho Alphitobius diaperinus (Panzer) (Coleoptera: Tenebrionidae). Neotropical Entomology, v.35, p.231-240, 2006. 
SAHAYARAJ, K.; BORGIO, J.F. Virulence of entomopathogenic fungus Metarhizium anisopliae (Metsch.) Sorokin on seven insect pests. Indian Journal of Agricultural Research, v.44, p. 195-200, 2010.

SANTORO, P.H.; NEVES P.M.O.J.; ALEXANDRE, T.M.; ALVES, L.F.A. Interferência da metodologia nos resultados de bioensaios de seleção de fungos entomopatogênicos para o controle de insetos. Pesquisa Agropecuária Brasileira, v.42, p.483-489, 2007.

SANTORO, P.H., NEVES, P.M.O.J., ALEXANDRE, T.M., SARTORI, D., ALVES, L.F.A., FUNGARO, M.E.P. Selection of Beauveria bassiana isolates to control Alphitobius diaperinus. Journal of Invertebrate Pathology, v.97, p.83-90, 2008.
WAQUIL, J.M.; VIANA, P.A.; CRUZ, I. Cultivo do Milho. Sete Lagoas: EMBRAPA MILHO E SORGO, 2006. (Documento Técnico). Disponível em: < http://sistemasdeproducao.cnptia.embrapa. br/FontesHTML/Milho/CultivodoMilho_2ed/prmonitoramento. htm>. Acesso em: 18 ago. 2012.

WRAIGHT, S.P.; RAMOS, M.E.; AVERY, P.B.; JARONSKI, S.T.; VANDERBERG, J.D. Comparative virulence of Beauveria bassiana isolates against lepidopteran of vegetable crops. Journal of Invertebrate Pathology, v.103, p.186-199, 2010.

XIAO, G.; YING, S.H.; ZHENG, P.; WANG, Z.L.; ZHANG, S.; XIE, X.Q.; SHANG, Y.S.T.; LEGER, R.J.; ZHAO, G.P.; WANG, C.; FENG, M.G. Genomic perspectives on the evolution of fungal entomopathogenicity in Beauveria bassiana. Scientific Reports, v.2, p.1-10, 2012. 